\title{
Necrotizing enterocolitis
}

\section{Controlled study of 3 years' experience in a neonatal intensive care unit}

\author{
G. L. BUNTON, G. M. DURBIN, N. McINTOSH, D. G. SHAW, A. TAGHIZADEH, \\ E. O. R. REYNOLDS, R. P. A. RIVERS, AND G. URMAN
}

\begin{abstract}
From the Departments of Paediatrics, Radiology, and Morbid Anatomy, University College Hospital and Medical School, London
\end{abstract}

SUMMARY During the 3 years 1972-74, 17 infants were treated for necrotizing enterocolitis (NEC) in the Neonatal Unit at University College Hospital. The incidence of the illness was $0.2 \%$ of live births in the hospital and $2.7 \%$ of those referred from elsewhere. The mean birthweight of the affected infants was $1832 \mathrm{~g}$ (range $878-3850 \mathrm{~g}$ ) and mean gestational age 33 weeks (range 28-40 weeks). The illness was diagnosed at a mean age of 16 days (range 3-33 days). 14 infants (82\%) survived. One infant developed NEC because of a volvulus, and another because of an apparently abnormal arterial supply to a segment of bowel. Each of the remaining 15 infants was matched with 3 control infants in order to see whether any factors predisposing to the development of NEC could be identified. Birth asphyxia, the use of umbilical catheters, the length of time that these catheters were in place, and complications of catheterization were all significantly more frequent in the infants who developed NEC than in the controls. These findings support the view that hypoxia and ischaemia of the gut wall are important in the pathogenesis of NEC.

Necrotizing enterocolitis (NEC) has been increasingly recognized in recent years as an important cause of serious illness and death in infants admitted to neonatal intensive care units (Waldhausen et al., 1963; Mizrahi et al., 1965; Touloukian et al., 1967; Fetterman, 1971; Stevenson et al., 1971; Stein et al., 1972; Hill et al., 1974; Roback et al., 1974; Livaditis et al., 1974; Virnig and Reynolds, 1974; Frantz et al., 1975; Santulli et al., 1975; Leonidas and Hall, 1976; Polin et al., 1976). The pathogenesis of the condition is imperfectly understood, though damage to the bowel mucosa followed by invasion with gasforming organisms have been suggested as important factors. The extensive literature has been reviewed by Santulli et al. (1975). We report details of infants with NEC admitted to the Neonatal Unit at University College Hospital (UCH) during a 3-year period. In order to obtain information about possible predisposing factors, clinical data from the affected infants and from a control group have been compared.

\section{Patients and methods}

Infants with NEC. During the 3-year period, January 1972 to December 1974, 17 infants were diagnosed as

Received 11 January 1977 having NEC. 9 were boys and 8 were girls. 10 were born in UCH and 7 were referred from other hospitals. Diagnosis was based on the presence of blood in the stool, abdominal distension, and vomiting, together with evidence from a plain $x$-ray film of gas in the bowel wall or portal venous system, fluid levels in the small intestine, or intestinal perforation. Clinical information from the 17 infants is in Table 1. In addition, 10 infants appeared peripherally vasoconstricted, and 8 had unstable rectal temperatures which varied by more than $1^{\circ} \mathrm{C}$ within a period of 6 hours. Haematological data were available from all 17 infants and detailed coagulation studies were carried out as previously described (Jones et al., 1972; Rivers, 1975) on 8.

Details of the total population of infants admitted to the neonatal unit during 1972-74 have been summarized by Blake et al. (1975). The perinatal mortality rate for infants born in $\mathrm{UCH}$ in the 3 years was $16 \cdot 2$ per 1000 births. The incidence of NEC was $0.2 \%$ of infants born in the hospital, and $2.7 \%$ of those referred from elsewhere, giving an overall incidence of $1.3 \%$ of admissions to the unit. One of the affected infants was referred because of NEC. The remainder developed the condition there.

Management and outcome. Except in one mildly 
affected infant, oral feeding was stopped and intravenous infusions of glucose and electrolytes were started as soon as the diagnosis was made. Nasogastric suction was started and all except 2 of the infants were treated with parenteral penicillin and gentamicin. 4 needed mechanical ventilation. None of the infants was given oral antibiotics though one was receiving colistin orally when NEC developed. 4 infants also received total parenteral nutrition as described by Shaw (1973).

Laparotomies were performed on 5 infants (Table 1), but in only one case (Case 12) during the acute stage of the illness. This infant was found to have infarction of the whole small intestine and ascending colon. She died after operation. The remaining 4 infants were operated upon aged 32-68 days, 8-45 days after NEC had been diagnosed. Surgery in one of these infants (Case 7) was for persistent bleeding from an ulcer in the transverse colon, which was excised, and in the others because of progressive abdominal distension and vomiting, together with radiological evidence of stricture formation. Strictures in the ileocaecal region were excised from 2 infants and the bowel was anastomosed. All made an uneventful recovery. A segment of the transverse colon in the remaining infant was found to be in spasm; this was left and she recovered spontaneously.

Two infants died without laparotomy. One (Case 5) arrived moribund from another hospital, and the other (Case 4) had extremely poor lung function due to hyaline membrane disease and massive pulmonary haemorrhage which precluded surgery.
Necropsies were performed on the 3 infants who died and pathological examination was carried out on the specimens removed at laparotomy. In one infant (Case 12), infarction of the bowel was found to be associated with a volvulus that had caused obstruction of the superior mesenteric artery. In another (Case 17) 3 strictures in the ileum were associated with an excess of thick walled and occluded small arteries which may have been congenital. Areas of necrosis and ulceration involving the mucosa and muscular layers of the bowel wall, particularly in the ileocaecal region were always found, and in 4 cases had resulted in perforation and peritonitis. Gas was seen in the bowel wall of 3 infants. The small blood vessels were ulcerated and thrombosed in all the infants except the one with the volvulus (Case 12), but apart from Case 17, no thrombic or embolic obstruction of the regional arteries could be shown. In the specimens removed at laparotomy the repair processes of the bowel wall were found to be well developed. A more detailed description of the pathological findings from infants treated in this hospital for NEC during the past 10 years will be published separately.

Controls. 3 control infants were selected for each of the 15 infants with NEC whose illness was not associated with a volvulus or a possible congenital abnormality (Cases 12 and 17). These 3 controls were admitted immediately before or after each NEC-affected infant, and their birthweights were within $7.5 \%$ of that of the affected infant. Controls

Table 1 Clinical and radiological features of the infants with necrotizing enterocolitis

\begin{tabular}{|c|c|c|c|c|c|c|c|c|c|c|c|c|c|c|}
\hline \multirow[b]{2}{*}{$\begin{array}{l}\text { Case } \\
\text { no. }\end{array}$} & \multirow[b]{2}{*}{$\begin{array}{l}\text { Birth- } \\
\text { weight } \\
(g)\end{array}$} & \multirow[b]{2}{*}{$\begin{array}{l}\text { Gest- } \\
\text { ation } \\
(w)\end{array}$} & \multirow[b]{2}{*}{$\begin{array}{l}\text { Day of } \\
\text { diagnosis }\end{array}$} & \multicolumn{5}{|c|}{ Clinical features } & \multicolumn{4}{|c|}{ Radiological findings } & \multirow[b]{2}{*}{$\begin{array}{l}\text { Surgery } \\
\text { (day) }\end{array}$} & \multirow[b]{2}{*}{ Outcome } \\
\hline & & & & $\begin{array}{l}\text { Abdom- } \\
\text { inal } \\
\text { disten- } \\
\text { sion }\end{array}$ & $\begin{array}{l}\text { Vomit- } \\
\text { ing }\end{array}$ & $\begin{array}{l}\text { Blood } \\
\text { in } \\
\text { stool }\end{array}$ & $\begin{array}{l}R h \\
\text { disease }\end{array}$ & $\begin{array}{l}\text { Umbilical } \\
\text { catheter* }\end{array}$ & $\begin{array}{l}\text { Gas in } \\
\text { bowel wall } \dagger\end{array}$ & $\begin{array}{l}\text { Gas in } \\
\text { portal } \\
\text { veins }\end{array}$ & $\begin{array}{l}\text { Fluid } \\
\text { levels } \\
\text { in small } \\
\text { intestine }\end{array}$ & $\begin{array}{l}\text { Perfor- } \\
\text { ation }\end{array}$ & & \\
\hline 1 & 878 & 33 & 7 & - & - & + & - & $\mathbf{a}$ & suspect, 1 & - & + & - & - & Survived \\
\hline 2 & 1123 & 29 & 22 & + & - & + & - & $\mathbf{a}$ & 1 & & + & - & 58 & " \\
\hline 3 & 1155 & 28 & 26 & + & - & + & - & $a+v$ & - & - & + & - & - & $"$ \\
\hline 4 & 1332 & 28 & 8 & + & - & + & - & a & $s+1$ & - & + & + & - & Died, day 10 \\
\hline 5 & 1438 & 30 & 17 & + & - & + & - & $\mathrm{v}$ & $s+1$ & + & + & - & - & Died, day 18 \\
\hline 6 & 1540 & 30 & 24 & + & + & + & - & - & $s+1$ & + & + & - & - & Survived \\
\hline 7 & 1595 & 31 & 24 & - & - & + & - & a & 1 & - & + & - & 32 & ," \\
\hline 8 & 1630 & 31 & 14 & - & + & + & - & $\mathbf{a}$ & suspect, 1 & - & $\begin{array}{l}\text { Erect film } \\
\text { not done }\end{array}$ & - & - & , \\
\hline 9 & 1641 & 31 & 33 & - & + & + & - & $\mathbf{a}$ & 1 & - & - & - & - & , \\
\hline 10 & 2200 & 35 & 10 & + & + & + & + & $\mathbf{a}$ & 1 & - & - & - & - & , \\
\hline 11 & 2200 & 35 & 5 & + & + & + & + & $\mathbf{a}$ & 1 & - & + & - & - & ," \\
\hline 14 & 2550 & 36 & 25 & - & + & + & + & $\mathrm{a}$ & - & - & + & - & - & ,, \\
\hline 15 & 2640 & 34 & 24 & - & - & + & + & $a+v$ & suspect. 1 & - & $\begin{array}{l}\text { Erect film } \\
\text { not done }\end{array}$ & $e^{-}$ & - & , \\
\hline 16 & 2776 & 36 & 10 & - & + & + & + & $a+v$ & 1 & - & - & - & - & ," \\
\hline 17 & 3850 & 40 & 5 & + & + & + & - & - & suspect, 1 & - & + & - & 50 & , \\
\hline Mean & 1832 & 33 & 16 Total & 10 & 9 & 17 & 5 & 14 & 11 & 3 & 12 & 1 & 5 infants & 14 survived \\
\hline Range & $878-3850$ & $28-40$ & (3-33) $\%$ & 59 & 53 & 100 & 29 & 82 & 65 & 18 & 70 & 6 & 29 & 82 \\
\hline
\end{tabular}

*a $=$ artery; $\mathrm{v}=$ vein $;+1=$ large intestine; $\mathrm{s}=$ small. 
with rhesus haemolytic disease were selected for the 5 NEC-affected infants with this disorder, but no attempt was made to match controls and infants with NEC for other illnesses.

The notes of all the infants were reviewed for factors which might have had an influence on the development of NEC. Statistical analysis was with the Pike Test for matched controls, and the Wilcoxon test.

\section{Results}

The results of comparisons between the infants with NEC and the controls are given in Table 2. Birth asphyxia, defined by a low Apgar score or delayed establishment of breathing, was more frequent in the infants who subsequently developed NEC. The presence of umbilical catheters, the length of time that they were in place, and the frequency of complications of catheterization, including decreased blood flow to the legs ( 2 infants), embolus to a toe (1 infant), recatheterization of the artery ( 3 infants), or umbilical sepsis ( 2 infants), were all significantly more common in the infants with NEC. The arterial catheters were $3.5 \mathrm{~F}$ or $5 \mathrm{~F}$ Argyle catheters with their tips sited at the level of the second to fourth lumbar vertebrae. When the umbilical vein was catheterized the catheter tip was in the inferior vena cava or portal sinus. The only infant with NEC among the 15 in the controlled study whose umbilical vessels were not catheterized (Case 6) received total parenteral nutrition via a silicon rubber catheter inserted percutaneously into the long saphenous vein at the ankle, with its tip at the level of the 12th thoracic vertebra.

The 5 NEC-affected infants with rhesus haemolytic disease received a total of 14 exchange transfusions (median 2, range 1-7, per infant). 8 were done through the artery and 6 through the vein. The umbilical arteries of 3 of the 5 infants were recatheterized for exchange transfusion. The veins were not recatheterized. 8 of the 15 control infants received 20 exchange transfusions through the artery and 8 through the vein; the umbilical artery of one infant and the umbilical veins of 4 control infants were recatheterized. No significant differences relating to exchange transfusion could be shown between the NEC-affected and control infants with rhesus haemolytic disease.

Coagulation findings from the 8 cases of NEC studied after the onset of illness showed thrombocytopenia (platelets $<150000 / \mathrm{mm}^{3} ; 150 \times 10^{9} / \mathrm{l}$ ) in 2 (Case 9, $107000 / \mathrm{mm}^{3}, 107 \times 10^{9} / 1$; Case 12, $\left.71000 / \mathrm{mm}^{3}, 71 \times 10^{9} / 1\right)$, evidence of hypercoagulability with a raised level of circulating fibrin monomer in 4 (Cases 9, 11, 12,13) and a high fibrinogen level ( $>600 \mathrm{mg} / 100 \mathrm{ml})$ in 2 (Cases 7 and 11). Disseminated intravascular coagulation was thought to exist in one infant (Case 12) because of very prolonged clotting times, thrombocytopenia, hypofibrinogenaemia, and high levels of fibrin degradation products. Haematological results from the 17 infants showed anaemia $(\mathrm{Hb}<10 \mathrm{~g} / \mathrm{dl})$ in 4 (Cases 2, 6, 7, 8), and an absolute neutropenia

Table 2 Comparison between infants with necrotizing enterocolitis and controls

\begin{tabular}{|c|c|c|c|}
\hline & $\begin{array}{l}\text { Infants with } \\
\text { necrotizing } \\
\text { enterocolitis } \\
(n=15)\end{array}$ & $\begin{array}{l}\text { Controls } \\
(n=45)\end{array}$ & $\boldsymbol{P}$ \\
\hline $\begin{array}{l}\text { Birthweight (g, mean } \pm S D) \\
\text { Gestation (w, mean } \pm \text { SD) } \\
\text { Sex ratio }(M: F) \\
\text { Birth asphyxia* (n) } \\
\text { Hyaline membrane disease (n) } \\
\text { Rhesus haemolytic disease (n) } \\
\text { Mechanical ventilation for respiratory illness (n) } \\
\text { Umbilical catheters (n) } \\
\text { Duration of umbilical catheterization (h, median + range) } \\
\text { Complications of umbilical catheterization } † \text { (n) } \\
\text { Pathogenic bacteria isolated }(n) \\
\text { Antibiotics } \S \text { given before diagnosis (n) } \\
\text { Antibiotics being given on day of diagnosis (n) } \\
\text { Feeding started with human milk (n) } \\
\text { Feeding with human milk continued until day of diagnosis (n) } \\
\text { Maximum volume of oral feed/day during the } 3 \text { days before diagnosis } \\
\text { (ml/kg per } 24 \text { h; median }+ \text { range) }\end{array}$ & $\begin{array}{l}1805 \pm 603 \\
32 \cdot 1 \pm 2 \cdot 9 \\
8: 7 \\
10(67 \%) \\
13(87 \%) \\
5(33 \%) \\
6(40 \%) \\
14(93 \%) \\
69(0-140) \\
8(53 \%) \\
8(53 \%) \\
9(60 \%) \\
2(13 \%) \\
13(87 \%) \\
5(33 \%) \\
\\
200(75-230)\end{array}$ & $\begin{array}{c}1805 \pm 605 \\
32 \cdot 0 \pm 3 \cdot 1 \\
24: 21 \\
10(33 \%) \\
24(53 \%) \\
15(33 \%) \\
11(24 \%) \\
29(64 \%) \\
30(0-144) \\
7(16 \%) \\
22(49 \%) \\
24(53 \%) \\
12(27 \%) \\
25(56 \%) \\
14(31 \%) \\
195(50-240)\end{array}$ & $\begin{array}{l}\text { NS } \\
\text { NS } \\
\text { NS } \\
<0 \cdot 0025 \\
\text { NS } \\
-\overline{N S} \\
<0 \cdot 0325 \\
<0 \cdot 025 \\
<0 \cdot 0025 \\
\text { NS } \\
\text { NS } \\
\text { NS } \\
\text { NS } \\
\text { NS } \\
\text { NS }\end{array}$ \\
\hline
\end{tabular}

* Apgar score $<5$ at one minute of age, $<7$ at $5 \mathrm{~min}$; or intubated and ventilated for more than $10 \mathrm{~min}$.

†mbolus, impaired circulation to the legs, recatheterization, or umbilical sepsis (see text).

†From admission or weekly routine cultures of nose, oropharynx, umbilicus, rectum, conjunctivae, or from daily cultures from endotracheal aspirate in intubated babies, or from blood cultures in sick babies. The only positive blood culture grew a Bacteroides (Case 1, Table 1). Peritoneal fluid from one infant (Case 4) grew Actinobacter.

§Penicillin and gentamicin. 
(polymorphonuclear granulocytes $<1500 / \mathrm{mm}^{3}$; $<1 \cdot 5 \times 10^{9} / 1$ ) in 1 (Case 4). No infant had been polycythaemic (venous haemotocrit $>65 \%$ ).

\section{Discussion}

The results of this investigation confirm that factors which cause hypoxia or ischaemia of the bowel wall are involved in the pathogenesis of NEC. One infant had a volvulus and another an apparently congenital abnormality of the blood supply to the gut. More affected infants than controls had low Apgar scores or were slow to breathe at birth and were therefore probably asphyxiated. Also, the incidence of hyaline membrane disease tended to be higher, though this difference was not significant. Asphyxia is known to provoke a redistribution of the circulation, including a large reduction in blood flow to the intestines (Lloyd, 1969; Touloukian et al., 1971, 1972), and Touloukian et al. (1972) showed in piglets that mucosal capillary engorgement and infarction occurred during recovery from ischaemia.

Catheterization of the umbilical vessels has previously been implicated in the pathogenesis of NEC (Beck et al., 1971; Hardy et al., 1972; Touloukian et al., 1973). In our study a higher proportion of affected than control infants had had their umbilical arteries or veins catheterized, and complications of catheterization, such as the replacement of arterial catheters, were much more common. Plastic catheters introduced through the umbilical artery into the aorta cause thrombus formation (Neal et al., 1972) which could compromise blood flow to the gut or encourage embolization. Necrosis and perforation of the bowel is a well recognized complication of exchange transfusion through the umbilical vein, probably because of stasis in the portal venous system (Orme and Eades, 1968; Rogers and Dunn, 1969; Beck et al., 1971; Hardy et al., 1972; Touloukian et al., 1973). The combination of asphyxia with umbilical catheterization seems especially likely to produce hypoxic or ischaemic damage to the bowel wall. The release of plasticizers from catheters is an additional factor that has been invoked in the pathogenesis of NEC (Rogers and Dunn, 1969; Hillman et al., 1975). A difficulty in directly relating umbilical catheterization to subsequent NEC in our investigation was that the illness did not develop until 2-29 (mean 13) days after the catheters were removed.

Other factors which may cause a reduction in blood flow or oxygen supply to the bowel are the presence of a large shunt (in either direction) through a patent ductus arteriosus (Kitterman, 1975); a high blood viscosity due to a high haematocrit; anaemia; hypotension; local inflammation due to the chemotactic effect of endotoxin released by Gram-negative organisms invading the bowel wall; and thrombosis in the microcirculation caused by the endotoxinstimulated release of a clot-promoting substance from monocytes (Rivers et al., 1975). Only one of the affected infants had the physical signs of a patent ductus arteriosus, and none were known to have been polycythaemic or hypotensive. However, the presence of anaemia in 4 infants may possibly have contributed to their illness by reducing oxygen delivery to the intestines. Evidence of hypercoagulability of the blood in another 4 suggests that endotoxin-stimulation of monocytes had occurred.

Engel et al. (1973) and Barlow et al. (1974) have shown in experimental animals that both bacterial colonization and the presence of a nutritive substrate in the bowel are necessary for the development of NEC-like changes following hypoxia. Barlow et al. (1974) further showed an effect of speciesspecific milk in preventing these changes from taking place. Although there was no difference in the proportion of breast milk fed infants in the NECaffected and control infants in the present study, the overall incidence of NEC was low when compared with most previous reports from neonatal intensive care units; the illness was generally mild and the survival rate was high, so breast milk may have been exerting a protective effect on our population of infants (Hanson et al., 1975). Any such effect could well have been incomplete, since the milk was usually pasteurized, which would be expected to destroy macrophages and inactivate other antibacterial substances in the milk. The remaining infants who developed NEC were being fed SMA, and none had received hyperosmolar feeds, which are capable of damaging the bowel wall (de Lemos, 1975).

Prevention. In the future, some of the factors implicated in this and previous studies in the development of NEC should become preventable. Asphyxia should become less frequent with improved fetal and postnatal monitoring. Silicon rubber may replace plastic as the material used for the manufacture of umbilical catheters (Boros et al., 1975), thereby reducing the risk of thrombosis and removing potential dangers associated with the presence of plasticizers. Also, the length of time that umbilical arterial catheters remain in situ is likely to become shorter as improvements continue to be made in the management of respiratory illnesses and in methods for transcutaneous monitoring of blood oxygen and carbon dioxide levels (Huch et al., 1972; Delpy and Parker, 1975). There is a case for feeding sick infants 
with fresh breast milk. We agree with Stein et al. (1975) that once NEC has developed a conservative approach to surgery is likely to yield the best results.

We are grateful to the staff of the Neonatal Unit and Professor J. F. Smith for help.

\section{References}

Barlow, B., Santulli, T. V., Heird, W. C., Pitt, J., Blanc, W. A., and Schullinger, J. N. (1974). An experimental study of acute neonatal enterocolitis-the importance of breast milk. Journal of Pediatric Surgery, 9, 587-595.

Beck, J. M., Dinner, M., and Chappel, J. (1971). Enterocolitis following exchange transfusion. South African Journal of Surgery, 9, 39-42.

Blake, A. M., McIntosh, N., Reynolds, E. O. R., and St. Andrew, D. (1975). Transport of newborn infants for intensive care. British Medical Journal, 4, 13-17.

Boros, S. J., Thompson, T. R., Reynolds, J. W., Jarvis, C. W., and Williams, H. J. (1975). Reduced thrombus formation with silicone elastomere (Silastic) umbilical artery catheters. Pediatrics, 56, 981-986.

de Lemos, R. A. (1975). Necrotizing Enterocolitis in the Newborn Infant. Proceedings of the Sixty-eighth Ross Conference on Pediatric Research, p. 82. Ross Laboratories, Columbus, Ohio.

Delpy, D., and Parker, D. (1975). Transcutaneous measurement of arterial blood-gas tensions by mass spectrometry. Lancet, 2, 1016.

Engel, R. R., Virnig, N. L., Hunt, C. E., and Levitt, M. D. (1973). Origin of mural gas in necrotizing enterocolitis. Pediatric Research, 7, 292.

Fetterman, G. H. (1971). Neonatal necrotizing enterocolitis. Pediatrics, 48, 345-348.

Frantz, I. D., L'Heureux, P., Engel, R. R., and Hunt, C. E. (1975). Necrotizing enterocolitis. Journal of Pediatrics, 86, 259-263.

Hanson, L. A., Carlsson, B., Ahlstedt, S., Svanborg, C., and Kaijser, B. (1975). Immune defense factors in human milk. Milk and Lactation, p. 63. Modern Problems in Paediatrics Vol. 15. Ed. by N. Kretchmer, E. Ross, and F. Sereni. Karger, Basel.

Hardy, J. D., Savage, T. R., and Shirodaria, C. (1972). Intestinal perforation following exchange transfusion. American Journal of Diseases of Children, 124, 136-141.

Hill, H. R., Hunt, C. E., and Matsen, J. M. (1974). Nosocomial colonisation with Klebsiella, type 26, in a neonatal intensive-care unit associated with an outbreak of sepsis, meningitis, and necrotizing enterocolitis. Journal of Pediatrics, 85, 415-419.

Hillman, L. S., Goodwin, S. L., and Sherman, W. R. (1975). Identification and measurement of plasticizer in neonatal tissues after umbilical catheters and blood products (1975). New England Journal of Medicine, 292, 381-386.

Huch, R., Lubbers, D. W., and Huch, A. (1972). Quantitative continuous measurement of partial oxygen pressure $\left(\mathrm{PO}_{2}\right.$ measurement) on the skin of adults and newborn babies. Pflügers Archiv, 337, 185-198.

Jones, C. E. M., Rivers, R. P. A., and Taghizadeh, A. (1972). Disseminated intravascular coagulation and fetal hydrops in a newborn infant in association with a chorangioma of placenta. Pediatrics, 50, 901-907.

Kitterman, J. A. (1975). Necrotizing Enterocolitis in the Newborn Infant. Proceedings of the Sixty-eighth Ross Conference on Pediatric Research, p. 35. Ross Laboratories, Columbus, Ohio.
Leonidas, J. C., and Hall, R. T. (1976). Neonatal pneumatosis coli: a mild form of neonatal necrotizing enterocolitis. Journal of Pediatrics, 89, 456-459.

Livaditis, A., Wallgren, G., and Faxelius, G. (1974). Necrotizing enterocolitis after catheterization of the umbilical vessels. Acta Paediatrica Scandinavia, 63, 277-282.

Lloyd, J. R. (1969). The etiology of gastrointestinal perforations in the newborn. Journal of Pediatric Surgery, 4, 77-84.

Mizrahi, A., Barlow, O., Berdon, W., Blanc, W. A., and Silverman, W. A. (1965). Necrotizing enterocolitis in premature infants. Journal of Pediatrics, 66, 697-706.

Neal, W. A., Reynolds, J. W., Jarvis, C. W., and Williams, H. J. (1972). Umbilical artery catheterization: demonstration of arterial thrombosis by aortography. Pediatrics, 50, 6-13.

Orme, R. L'E., and Eades, S. M. (1968). Perforation of the bowel in the newborn as a complication of exchange transfusion. British Medical Journal, 4, 349-351.

Polin, R. A., Pollack, P. F., Barlow, B., Wigger, H. J., Slovis, T., Santulli, T. V., and Heird, W. C. (1976). Necrotizing enterocolitis in term infants. Journal of Pediatrics, 89, 460-462.

Rivers, R. P. A. (1975). Coagulation changes associated with a high haematocrit in the newborn infant. Acta Paediatrica Scandinavica, 664, 449-456.

Rivers, R. P. A., Hathaway, W. E., and Weston, W. L. (1975). The endotoxin-induced coagulant activity of human monocytes. British Journal of Haematology, 30, 311-316.

Roback, S. A., Foker, J., Frantz, I. D., Hunt, C. E., Engel, R. R., and Leonard, A. S. (1974). Necrotizing enterocolitis. An emerging entity in the regional infant intensive care facility. Archives of Surgery, 109, 314-319.

Rogers, A. F., and Dunn, P. M. (1969). Intestinal perforation, exchange transfusion and PVC. Lancet, 2, 1246.

Santulli, T. V., Schullinger, J. N., Heird, W. C., Gongaware, R. D., Wigger, J., Barlow, B., Blanc, W. A., and Berdon, W. E. (1975). Acute necrotizing enterocolitis in infancy: a review of 64 cases. Pediatrics, 55, 376-387.

Shaw, J. C. L. (1973). Parenteral nutrition in the management of sick low birthweight infants. Pediatric Clinics of North America, 20, 333-358.

Stein, H., Beck, J., Solomon, A., and Schmaman, A. (1972). Gastroenteritis with necrotizing enterocolitis in premature babies. British Medical Journal, 2, 616-619.

Stein, H., Kavin, I., and Faerber, E. N. (1975). Colonic strictures following nonoperative management of necrotizing enterocolitis. Journal of Pediatric Surgery, 10, 943-947.

Stevenson, J. K., Oliver, T. K., Graham, C. B., Bell, R. S., and Gould, V. E. (1971). Aggressive treatment of neonatal necrotizing enterocolitis: 38 patients with 25 survivors. Journal of Pediatric Surgery, 6, 28-35.

Touloukian, R. J., Berdon, W. E., Amoury, R. A., and Santulli, T. V. (1967). Surgical experience with necrotizing enterocolitis in the infant. Journal of Pediatric Surgery, 2, 389-401.

Touloukian, R. J., Spencer, R. P., and Stinson, K. K. (1971). Alimentary circulation in the pup during the postnatal period. Archives of Surgery, 102, 516-520.

Touloukian, R. J., Posch, J. N., and Spencer, R. (1972). The pathogenesis of ischemic gastroenterocolitis of the neonate: selective gut mucosal ischemia in asphyxiated neonatal piglets. Journal of Pediatric Surgery, 7, 194-205.

Touloukian, R. J., Kadar, A., and Spencer, R. P. (1973). The gastrointestinal complications of neonatal umbilical venous exchange transfusion: a clinical and experimental study. Pediatrics, 51, 36-43. 
Virnig, N. L., and Reynolds, J. W. (1974). Epidemiological aspects of neonatal necrotizing enterocolitis. American Journal of Diseases of Children, 128, 186-190.

Waldhausen, J. A., Herendeen, T., and King, H. (1963). Necrotizing colitis of the newborn: common cause of perforation of the colon. Surgery, 54, 365-375.
Correspondence to Dr. G. M. Durbin, Department of Paediatrics, University of Birmingham, East Birmingham Hospital Teaching Unit, East Birmingham Hospital, Bordesley Green East, Birmingham B9 5ST.

The following articles will appear in future issues of this journal:

Neurological complications of childhood leukaemia. R. H. A. Campbell, W. C. Marshall, and Judith M. Chessells.

Pressure and volume changes during the first breath of human neonates. A. D. Milner and R. A. Saunders. Clinical, physiological, and psychological study of asthmatic children attending a hospital clinic. Mary Norrish, Marian Tooley, and S. Godfrey.

Hyperlipidaemia in children on regular haemodialysis. M. El-Bishti, R. Counahan, R. J. Jarrett, L. Stimmler, $V$. Wass, and C. Chantler.

Increased protoporphyrin in erythrocytes in a child with acute intermittent porphyria. Anita Gregor, Ewa Kostrzewska, Halina Prokurat, Zofia Pucek, and Emilia Torbicka.

Bladder emptying in neonates. J. Osborne, G. du Mont, M. Beecroft, and A. B. Ayres.

Lung function in children after repair of congenital diaphragmatic hernia. A. A. Kerr. 